\title{
An experimental study of the effect of the projection ratio and throat-aspect ratio on the efficiency and loss coefficient of a water jet pump
}

\author{
M.P. Helios ${ }^{1,3}$ and W. Asvapoositkul ${ }^{2}$ \\ ${ }^{1}$ The Joint Graduate School of Energy and Environment, King Mongkut's University of Technology Thonburi, Bangkok, Thailand \\ 2 Department of Mechanical Engineering, Faculty of Engineering, King Mongkut's University of Technology Thonburi, Bangkok, Thailand \\ Phone: (662) 470-9123; Fax: (662) 470-9111 \\ ${ }^{3}$ Center of Excellence on Energy Technology and Environment (CEE), PERDO, Ministry of Higher Education, Science, Research and Innovation, \\ Bangkok, Thailand
}

\begin{abstract}
This study focuses on the influence of dimensionless geometry parameters on the performance and loss coefficient of the throat and diffuser of the water jet pump apparatus. A water jet pump system was designed for a total of nine experimental cases with three different projection ratios $\left(L_{x}^{*}\right)$ and three throat-aspect ratios $\left(L_{t}^{*}\right)$. The volumetric and pressure ratios - performance parameters are measured at a constant motive pressure and under varying backpressure. The efficiencies of the water jet pump in each configuration were assessed and compared. It was found that increasing 2 or 3 times of projection ratio degrades efficiency about $2 \%$ to $5.5 \%$, respectively. Higher projection ratio $\left(L_{x}^{*}>1\right)$ expands the water jet diameter, which clogs the secondary flow. Hence, the changes in $L_{x}^{*}>3$ may have a significant impact on efficiency degradation. Shorter $L_{t}^{*}$ may cause the loss of kinetic energy in the diffuser, while longer $L_{t}^{*}$ reduces momentum transfer on the secondary flow. Moreover, the changes in $L_{x}^{*}$ and $L_{t}^{*}$ influence friction loss coefficient in the throat and diffuser section, and it reduces with increasing of volumetric ratio. It can be concluded that the appropriate value of projection ratio and throat-aspect ratio plays a role in the kinetic energy dissipation. It is also responsible for the location friction process, at a different volumetric ratio. However, the experimental results denoted the best efficiency and loss coefficient was achieved at a low projection ratio $\left(L_{x}^{*}=1\right)$ and small throat-aspect ratios $\left(L_{t}^{*}=5\right)$. The best efficiency of the study was about $23.37 \%$.
\end{abstract}

ARTICLE HISTORY

Received: $20^{\text {th }}$ May 2020

Revised: $28^{\text {th }}$ Jan 2021

Accepted: $25^{\text {th }}$ Feb 2021

\section{KEYWORDS}

Water jet pump;

throat-aspect ratio;

projection ratio;

efficiency;

friction loss coefficient.

\section{INTRODUCTION}

A jet pump is one of the artificial lift equipment, which works by transferring momentum from the high-velocity primary flow to the secondary flow. It has been widely used in various distinct situations and industrial processes. A typical jet pump is mainly composed of a nozzle, a suction chamber, a throat pipe, and a diffuser (see Figure 1(a)). The main features of the jet pump are the absence of rotating parts, simple structure, reliability, durability, and relatively low cost [1]. A good design of jet pump should have $20 \%$ to $40 \%$ efficiency [2]. However, according to the efficiency range, the jet pump still faces the inefficiency problem. The problem is commonly caused by cavitation [3-6], recirculation [7, 8], mixing [9], and separation [10] in the process. The phenomena can be analysed by measuring the wall pressure gradient or by capturing the phenomena.

Long et al. [3] observed three phenomena of cavitation, such as incipient, developing, and intensive, which are under an operating limit condition decreased outlet pressure close to atmospheric condition. The results have shown that the cavitation presented in the forms of bubble-like and ribbon-like to the intensive cloud. The phenomena occur in the concurrent, throat, and diffuser sections. In this situation, the secondary/entrained flow is stable. To verify the phenomena, Xiao et al. [5] confirmed that cavitation modelling is validated using a similar condition of observation results by numerical simulation. Under normal working conditions, the efficiency curve is achieved by adjusting the pressure outlet, and the curve is divided into three conditions, i.e., choked, unchoked, and reversed flow. Firstly, the jet pump chokes and entrains the secondary flow, where it also maintains the increased backpressure at the same time. Later, the secondary flow rate decreases rapidly in specific critical backpressure. The kinetic energy of the primary jet flow is dissipated for maintaining the backpressure. As a result, the recirculation appears and reduces the secondary flow. Wang et al. [6] compared different profiles of the suction chamber and throat-entry i.e. polygonal and streamline profiles to reduce the effect of cavitation on water jet pump performance. The results claimed that the pump efficiency increased by $1.4 \%$ using the streamline profile. Since the surface of the throat was smoothly connected with the suction chamber, the flow separation and local low pressure did not appear. The detailed phenomena modelling and visualising of the phenomena via numerical and experimental can be found in Xiao et al. [7, 8]. Lastly, there is no secondary flow at over the limit of backpressure. The reversed flow floods the chamber. Similar to cavitation, the reversed flow can be identified by loud noise and vibration in this system $[9,10]$. Due to interrelatedness phenomena to the efficiency of jet pump, it is possible 
to be controlled by appropriate combination among operating conditions $[11,12]$, geometry structures [13-18], fluid properties [19-21] and location of jet pump installation [22-25]. Nasr et al. [13] studied the experimental and numerical performance of water jet pump over a large range area ratio, throat-aspect ratios and diffuser angle at the submerged condition. They claimed that the jet pump dimension with an area ratio of 0.27 , throat-aspect ratio of 5.5 and diffuser angle $5^{\circ}$ has the best efficiency. Toteff and Tovar [17] investigated water jet pump performance in a closed pipeline loop via numerical simulation. The results claimed that

According to the location of the mixing phenomena in the water jet pump geometry, the projection ratio $\left(L_{x}^{*}=\frac{x}{d_{t}}\right)$ and throat-aspect ratio $\left(L_{t}^{*}=\frac{l_{t}}{d_{t}}\right)$ as independent dimensionless parameters were considered for improving jet pump efficiency. Both ratios offer the possibility of efficiency improvement of about $2.5 \%$ and 5\%, respectively [26, 27]. However, few researchers have tried to find and to report optimum projection and throat-aspect ratios in their studies [28, 29]. The proportional projection ratio and throat-aspect ratio for water jet pumps based on the previous literature are recommended from 0.5 to 1.25 and from 5 to 10 , respectively [27-33]. This range is acceptable but is not justified due to a lack of relation to operating condition, dimension, and direction system. Hammoud \& Naby [32] studied optimum efficiency under different motive pressure and projection ratios on transporting water and slurry. The study results claimed that the optimum efficiency of transporting water was obtained by driving pressure $150 \mathrm{kPa}$ at $L_{x}^{*}=1$, while $300 \mathrm{kPa}$ at $L_{x}^{*}=1.25$ for slurry. El-Sawaf et al.[33] also stated that the optimum efficiency of the water jet pump was achieved at $L_{x}^{*}$ $=1$ and $L_{t}^{*}=7.25$. Mekhail \& Teaima [34] reported that $L_{x}^{*}=0.5$ at $150 \mathrm{kPa}$ was the optimum condition of transporting water. Nonetheless, $L_{x}^{*}$ less than 0.5 was not recommended due to cavitation $[6,26,30]$.

Apart from efficiency, moving position and extending part may increase energy losses. The losses of mechanical energy in favour of internal energy dominate losses in a flow field. In the first law of thermodynamics, the conversion process of both energy forms conserves the overall energy [35]. From a fluid mechanics point of view, a single conduit component of an internal flow path, i.e., straight tubes, bends, contraction and expansion channels are known as friction loss coefficients. The internal flows in the conduit can be estimated by pressure drop [36]. However, it is only equivalent to a loss of mechanical energy when the kinetic and potential energies in cross-sections are unchanged [37]. The efficiency of the water jet pump is directly affected by the throat-diffuser friction loss coefficient $\left(K_{t d}\right)$ representing the sum of loss coefficient between the throat $\left(K_{t}\right)$ and diffuser $\left(K_{d}\right)$. The value is used as an assumption in design and required to be reevaluated after testing. The actual $K_{t}$ is changed with an increasing volumetric ratio due to extended or persisted mixing process. In the diffuser, the sudden rise of $K_{d}$ may have informed the separation process in the diffuser wall [27, 30]. However, most of the previous studies omitted the pressure taps on the throat section. Therefore, it limited the evaluation of $K$ based on experimental testing.

To the best knowledge of the authors, there is no further discussion concerning the relationship between both parameters, i.e. $L_{x}^{*}$ and $L_{t}^{*}$ to optimise the efficiency and friction loss coefficient. Both parameters are essential to achieve a better understanding of the effects of geometry on generating friction resistance, which influences water jet pump performance. The study of both independent parameters is still required to enhance and encourage the efficiency of the water jet pump. Furthermore, this study is aimed to achieve the best efficiency and evaluate the throat and diffuser loss coefficient of the water jet pump by varying projection ratio and throat-aspect ratio via experiment.

\section{EXPERIMENTAL SETUP}

Water Jet Pump and Parameter of Study

Figure 1(a) depicts the water jet pump assembly used in this experiment. It consists of five modular components i.e. nozzle, suction chamber, convergent, throat and diffuser, which are connected using hex bolts and nuts. The original water jet pump dimension is taken from the Technology Laboratory for Thermodynamics, Engines and Propulsion, Agency for The Assessment and Application of Technology in Indonesia. It is designed by adopting ESDU standards [38], and it is used for varying purposes of fulfilling the power generation and agricultural industry needs in Indonesia. The final design parameter of a central-driven water jet pump and its relation is summarised in Table 1. All the dimensions refer to the notation in Figure 1(b). The projection ratio $\left(L_{x}^{*}\right)$ and throat-aspect ratio $\left(L_{t}^{*}\right)$ are equal to 1 and 7 , and are selected based on postulate in the literature. The water jet pump assembly was designed to be fabricated and tested to obtain actual efficiency. It was made using stainless-steel (SS-304) material due to its high resistance and durability for future research studies. 


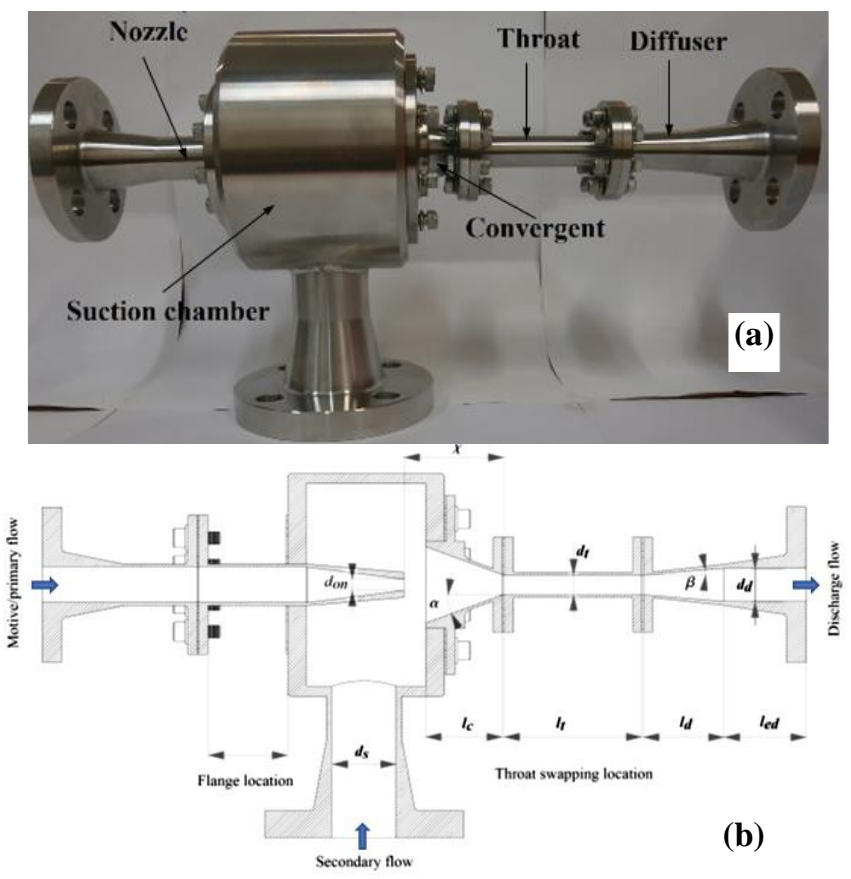

Figure 1. Water jet pump: (a) assembly and (b) schematic parameters of the study

Table 1. The dimension of the water jet pump

\begin{tabular}{cccc}
\hline Parameter & Symbol \& relation & Unit & Value \\
\hline Outlet nozzle diameter & $d_{o n}$ & $\mathrm{~mm}$ & 7.1 \\
Throat diameter & $d_{t}$ & $\mathrm{~mm}$ & 12.7 \\
Diffuser diameter & $d_{d}$ & $\mathrm{~mm}$ & 18.9 \\
Distance between the nozzle tip and throat-entry & $x$ & $\mathrm{~mm}$ & 12.7 \\
Throat length & $l_{t}$ & $\mathrm{~mm}$ & 88.9 \\
Diffuser extended length & $l_{e d}$ & $\mathrm{~mm}$ & 52.4 \\
Converging section angle & $\alpha$ & $\mathrm{o}$ & 20.0 \\
Diverging/diffuser angle & $\beta$ & $\mathrm{o}$ & 3.5 \\
\hline
\end{tabular}

Essentially, the selection of an appropriate projection ratio $\left(L_{x}^{*}\right)$ and throat-aspect ratio $\left(L_{t}^{*}\right)$ is the first step to achieving standard design efficiency. Both parameters are selected due to the significant influences on the main flow field behaviour. The projection ratio is related to the momentum transfer and cavitation process, while the throat-aspect ratio is related to the mixing process and friction loss. Hence, a total of nine cases of water jet pump configurations have been provided, as listed in Table 2.

Table 2. Matrix of experimental testing

\begin{tabular}{ccc}
\hline \multirow{2}{*}{$\begin{array}{c}\text { Testing } \\
\text { No. }\end{array}$} & \multicolumn{2}{c}{ Parameters } \\
\cline { 2 - 3 } & $L_{x}^{*}=\frac{x}{d_{t}}$ & $L_{t}^{*}=\frac{l_{t}}{d_{t}}$ \\
\hline 1 & 1 & 5 \\
2 & 1 & 7 \\
3 & 1 & 9 \\
4 & 2 & 5 \\
5 & 2 & 7 \\
6 & 2 & 9 \\
7 & 3 & 5 \\
8 & 3 & 7 \\
9 & 3 & 9 \\
\hline
\end{tabular}




\section{Test Facility and Instrumentation}

The experimental testing of the jet pump was constructed in the Mechanical Department, King Mongkut's University of Technology Thonburi (see Figure 2). As a closed-loop system, it consisted of the main components, including a centrifugal pump, a water tank, and a jet pump and its instrumentations. A water tank, $1 \times 1 \times 6 \mathrm{~m}^{3}$, was placed under the jet pump as a water supply storage. The tank was filled with water, about $60 \%$ of total volume, to maintain a constant water level as well as to be head suction of secondary flow. The jet pump was installed above the tank with the support frame to minimise the effect of vibration. A centrifugal pump was connected with a $3 / 4$ inch (20 mm) nominal pipe size, which was set beside the sidewall of the water tank. It delivered a constant flow rate of water to the chamber and entrained the secondary flow in a $0.90 \mathrm{~m}$ long suction pipe with $1 \frac{1 / 2}{2} \mathrm{inch}(38.1 \mathrm{~mm})$ nominal pipe size. The inlet of the suction pipe was submerged under the water surface to prevent bubble formation from returning to the inlet of the system. The discharge fluid was transported to the tank at atmospheric condition using $3 / 4$ inch $(20 \mathrm{~mm})$ nominal pipe size of the PVC pipe. Then, other instrumentations were installed to measure the volumetric flow rate, pressure, and temperature simultaneously.

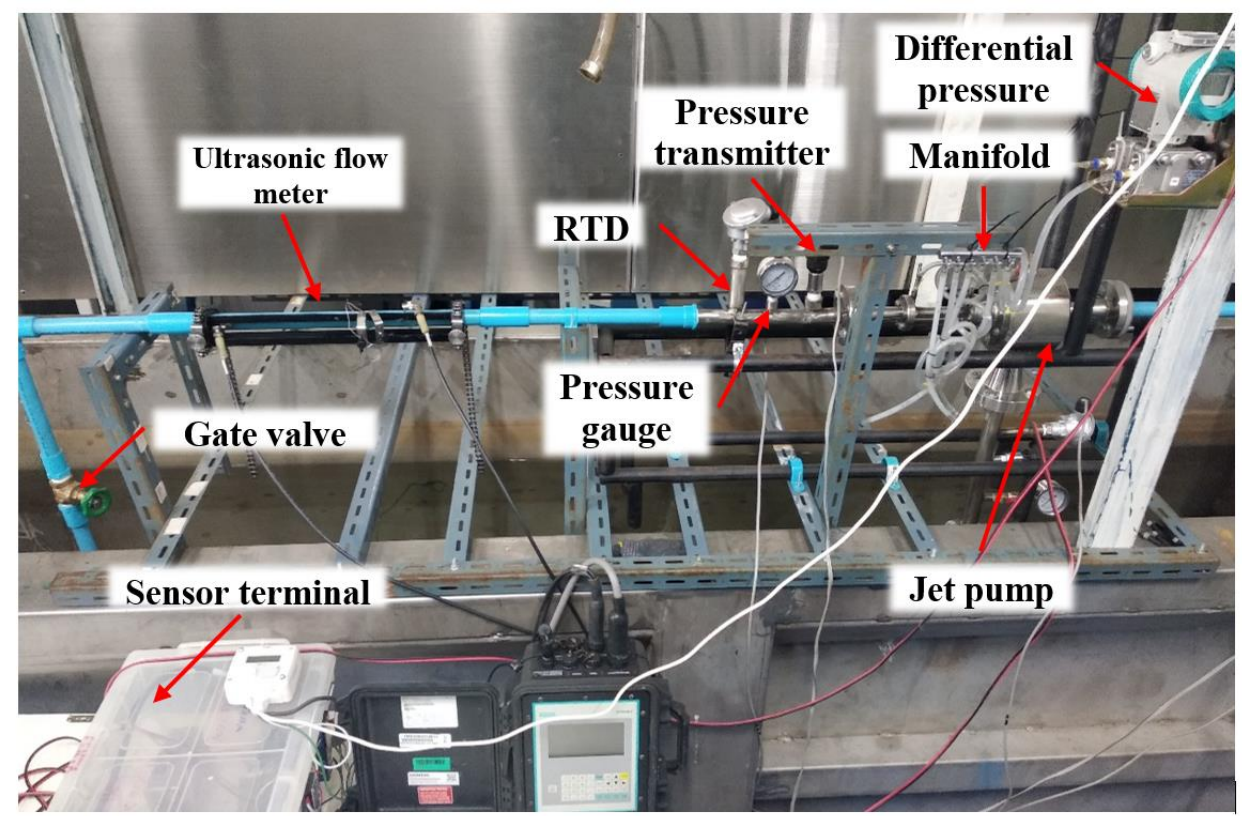

Figure 2. Photograph of jet pump test rig

The water flow rate of primary and discharge flows was measured by using calibrated rotameter and ultrasonic flow meter, respectively. The secondary flow rate was known by quantifying the difference between both streams. Further, three pressure transmitters and three RTDs were attached at inlets and outlet. The pressure transmitters recorded the pressure of inlets and outlet, while the RTD's were used to monitor the temperature of each stream. Since the experiment used a single tank and circulated the water frequently, the temperature sensor was required to achieve the isothermal process. Moreover, a differential pressure was attached to measure the pressure difference in the throat section. The data were stored in the data acquisition and utilised to determine the efficiency of the jet pump using the LabView program. The detail sensor used in this experiment is summarised in Table 3.

Table 3. Measuring device specification

\begin{tabular}{cccccc}
\hline Device & Notation & Unit & Range & Accuracy (\%) & Resolution \\
\hline \multirow{2}{*}{ Flowmeter } & $Q_{d}$ & $\mathrm{~L} / \mathrm{min}$ & 0 to 150 & 0.25 & 0.001 \\
& $Q_{p}$ & $\mathrm{~L} / \mathrm{min}$ & 0 to 100 & 4.00 & 0.1 \\
& $P_{p}$ & $\mathrm{kPa}$ & 0 to 400 & 0.30 & 0.001 \\
Pressure & $P_{s}$ & $\mathrm{kPa}$ & -100 to 100 & 0.30 & 0.001 \\
& $P_{d}$ & $\mathrm{kPa}$ & 0 to 400 & 0.30 & 0.001 \\
Temperature & $\Delta P$ & $\mathrm{kPa}$ & 0 to 160 & 0.25 & 0.001 \\
& $T_{p}$ & $\mathrm{~K}$ & 273 to 323 & 0.25 & 0.001 \\
& $T_{s}$ & $\mathrm{~K}$ & 273 to 323 & 0.25 & 0.001 \\
\hline
\end{tabular}




\section{Measurement Procedures}

At first, the projection ratio was set by inserting the flat flanges or spacer with a different thickness between the nozzle and chamber body. By entering and adding some spacers, $L_{x}^{*}$ changed from 1 to 3 . Afterwards, the throat-aspect ratio was replaced by swapping three different throat length (see Figure 1). The experimental procedure was described in this section (refer to Figure 3) as the efficiency curve. The figure shows the flow rate of primary fluid, which was circulated by using a centrifugal pump with a constant flow rate to nozzle at driving pressure $400 \mathrm{kPa}$ absolute. The water jet generated momentum and entrained secondary fluid from the bottom side of the chamber. Both streams were mixed along the throat to the diffuser section and discharged by extending piping and by returning the water into the tank.

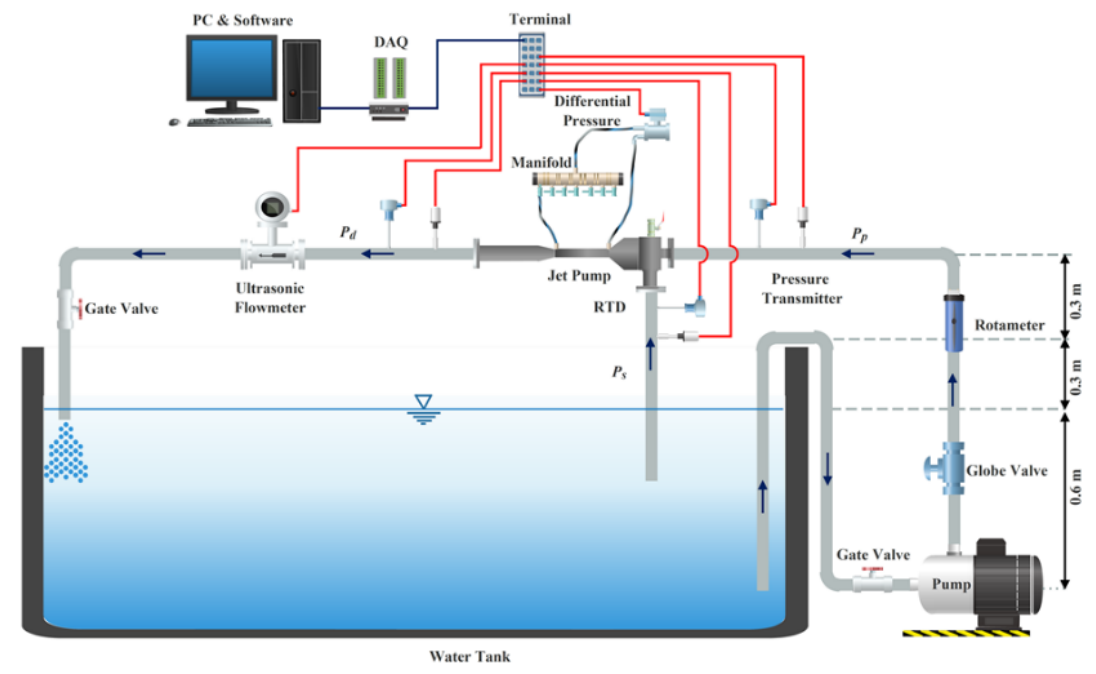

Figure 3. Schematic of water jet pump closed-loop system

After the steady-state condition of a loop system is achieved, the backpressure was initiated by blocking the discharge flow by using a gate valve attached at the end of the elbow. It starts from the fully open condition, and then the valve closes slowly corresponding with increasing back pressure from $140 \mathrm{kPa}$ to $240 \mathrm{kPa}$ absolute with $10 \mathrm{kPa}$ intervals. At this condition, the discharge area turns smaller, and the flow detained in the pipe. When the stability of backpressure was obtained for each interval, the data acquisition system recorded the data of each sensor, i.e., pressure, temperature, and the volume flow rate. Each sensor collected 60 sample data each minute for one data point during the 5 minute period. At the same time, the increase of backpressure was able to notice directly via pressure gauge or data acquisition interface on a computer. Further, a similar procedure was applied repeatedly for each configuration.

Along with that, the analysis of experimental uncertainty is imperative to obtain the proper elucidation of experimental results. The uncertainty of measurement of each sensor and parameter is calculated by using standard procedure ASME PTC 19.1-2005 of test uncertainty [39]. The analysed measurement uncertainties were also found and applied to the method presented by Kline and McClintock [40]. The data sample of optimum efficiency was used to assess uncertainties. The combined uncertainty results of measured and calculated variables in the percentage are summarised in Table 4.

Table 4. Uncertainty $\left(\overline{\boldsymbol{U}}_{\boldsymbol{R}, 95}\right)$ of variables

\begin{tabular}{ccccccccc|ccc}
\hline \multicolumn{10}{c|}{ Measured (\%) } & \multicolumn{3}{c}{ Calculated (\%) } \\
\hline $\boldsymbol{Q}_{\boldsymbol{p}}$ & $\boldsymbol{Q}_{\boldsymbol{d}}$ & $\boldsymbol{P}_{\boldsymbol{p}}$ & $\boldsymbol{P}_{\boldsymbol{s}}$ & $\boldsymbol{P}_{\boldsymbol{d}}$ & $\boldsymbol{\Delta P}$ & $\boldsymbol{T}_{\boldsymbol{p}}$ & $\boldsymbol{T}_{\boldsymbol{s}}$ & $\boldsymbol{T}_{\boldsymbol{d}}$ & $\boldsymbol{Q}^{*}$ & $\boldsymbol{P}^{*}$ & $\boldsymbol{\eta}$ \\
\hline 1.62 & 0.37 & 0.03 & 0.05 & 0.08 & 0.8 & 0.11 & 0.11 & 0.11 & 1.93 & 0.24 & 0.95 \\
\hline
\end{tabular}

\section{Performance and Loss-Coefficient Evaluation}

Principally, the primary liquid $\left(Q_{p}\right)$ in the jet, pumps entrain secondary fluid $\left(Q_{s}\right)$ at lower pressure conditions and transport it to the discharge at a particular pressure condition. Two non-dimensionless ratios, i.e., the volumetric ratio $\left(Q^{*}\right)$ and pressure ratio $\left(P^{*}\right)$ are introduced as efficiency parameters. Both parameters can be written as follows [27, 34]:

$$
\begin{gathered}
Q^{*}=\frac{Q_{s}}{Q_{p}}=\frac{\text { Volume flow rate of secondary fluid }}{\text { Volume flow rate of primary fluid }} \\
P^{*}=\frac{P_{d}-P_{s}}{P_{p}-P_{d}}=\frac{\text { Secondary fluid pressure rise }}{\text { Primary fluid pressure drop }}
\end{gathered}
$$


Where $Q$ and $P$ represent the volume flow rate $(\mathrm{L} / \mathrm{min})$ and absolute pressure $(\mathrm{Pa})$, while subscript $p, s$, and $d$ stand for primary, secondary and discharge respectively (see Fig. 1). Hence, the efficiency of the jet pump $(\eta)$ the equation can be written as follows:

$$
\eta=\frac{Q_{s}}{Q_{p}} \times \frac{P_{d}-P_{s}}{P_{p}-P_{d}}=\frac{\text { Energy gained in secondary fluid }}{\text { Energy supplied by primary fluid }}
$$

Besides efficiency, this study focuses on an analysis of friction loss coefficient $(K)$, i.e., throat and diffuser. Both loss coefficients dominate energy loss in the water jet pump with changes in volumetric ratio. The value of $K$ can be estimated by using the equation as follows [35]:

$$
K=\frac{\Delta P}{\frac{1}{2} \rho_{p} \mathrm{v}_{t}^{2}}
$$

Where $\Delta P, \rho_{p}$ and $\mathrm{v}_{t}$ represent the pressure drop $(\mathrm{Pa})$, primary fluid density $\left(\mathrm{kg} / \mathrm{m}^{3}\right)$ and velocity in throat entry $(\mathrm{m} / \mathrm{s})$, respectively.

\section{RESULTS AND DISCUSSION}

\section{Effect of Projection Ratio and Throat-Aspect Ratio}

Three sets of different projection ratios are adjusted by using spacers. The experiment was tested and studied for each projection ratio and was combined with varying throat-aspect ratio equal from 5 to 9 . First, the secondary flow rate of each configuration was analysed during an increase of backpressure. The variations of the secondary flow rate $\left(Q_{s}\right)$ with backpressure $\left(P_{d}\right)$ is shown in Figure 4 . It reveals that an increase in projection ratio $\left(L_{x}^{*}\right)$ and throat-aspect ratio $\left(L_{t}^{*}\right)$ tends to decrease $Q_{s}$. Higher $Q_{s}$ is achieved at $L_{x}^{*}=1$ compared with that at $L_{t}^{*}=5, L_{t}^{*}=7$ and $L_{t}^{*}=9$. The increasing $L_{x}^{*}$ causes generating friction resistance between primary and secondary fluid. Both flows collide in the bottleneck region and generate shear flow due to different velocity [20]. Higher $Q_{s}$ is observed at $L_{t}^{*}=5$ compared with that at $L_{x}^{*}=1, L_{x}^{*}=$ 2 and $L_{x}^{*}=3$. It is due to friction resistance between mixed flow and throat wall which affects the pressure drop that occurred during the mixing process. Therefore, both parameters do not affect significantly to $P_{d}$. Increasing $P_{d}$ tends to decrease $Q_{s}$ linearly.
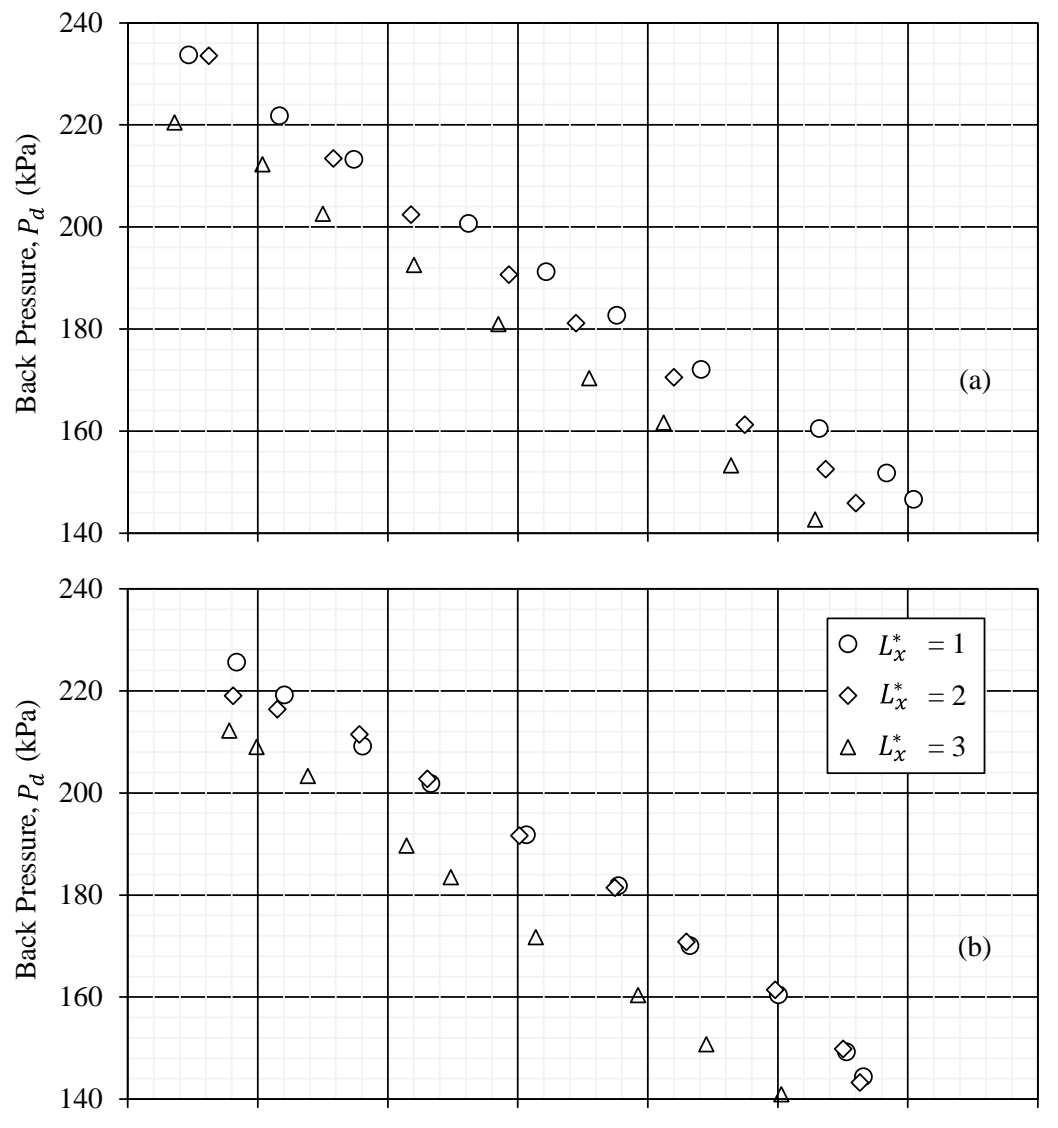


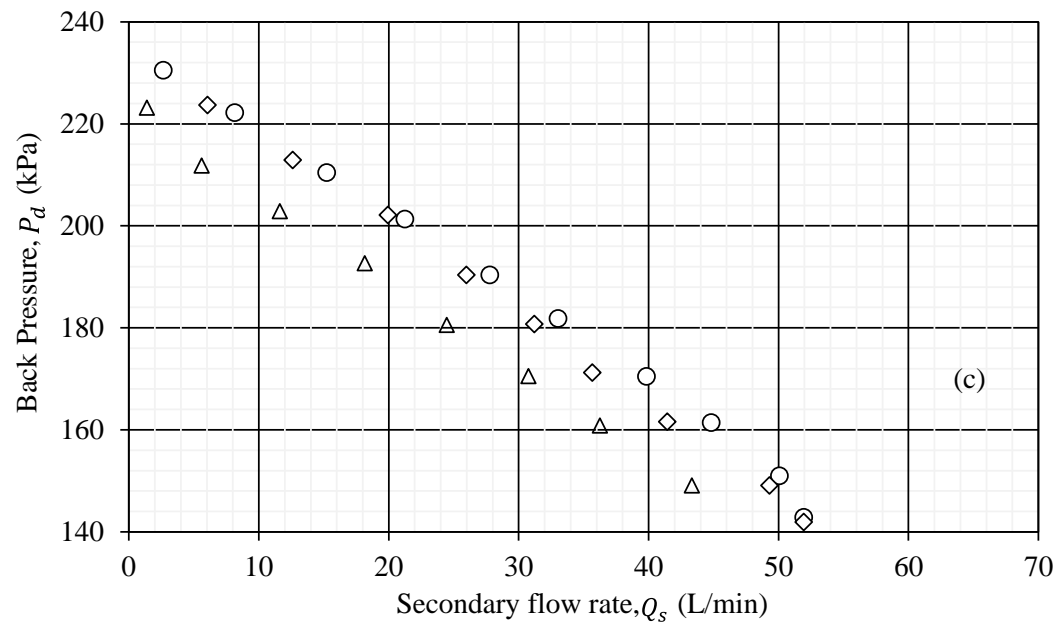

Figure 4. Secondary flow rate vs. back pressure at difference projection ratio and throat-aspect ratio: (a) $\boldsymbol{L}_{\boldsymbol{t}}^{*}=5$, (b) $\boldsymbol{L}_{t}^{*}=7$ and (c) $\boldsymbol{L}_{t}^{*}=9$

Figure 5 shows the influence of $L_{x}^{*}$ and $L_{t}^{*}$ on pressure ratio and water, jet pump efficiency. Increasing the lengths of $L_{x}^{*}$ and $L_{t}^{*}$ mean increased friction in the process. The result shows that the pressure ratio decreases with increasing volumetric ratio and tends to be in a linear relation. The maximum volumetric ratio $\left(Q_{\max }^{*}\right)$ in each test, the condition decreases with increasing $L_{x}^{*}$ or $L_{t}^{*}$. For instance, $Q_{\max }^{*}$ decreases from 1 to 0.87 when $L_{t}^{*}$ increases from 5 to 9 at $L_{x}^{*}=1$. The decrease in pressure and volumetric ratios are due to the mixing process and friction in the throat section [28]. Also, the maximum efficiency in each test condition decreases with increasing $L_{x}^{*}$ or $L_{t}^{*}$. The highest efficiency was at $\eta=$ $23.37 \%$ with $L_{x}^{*}=1$ and $L_{t}^{*}=5$ as shown in Figure 5(a).
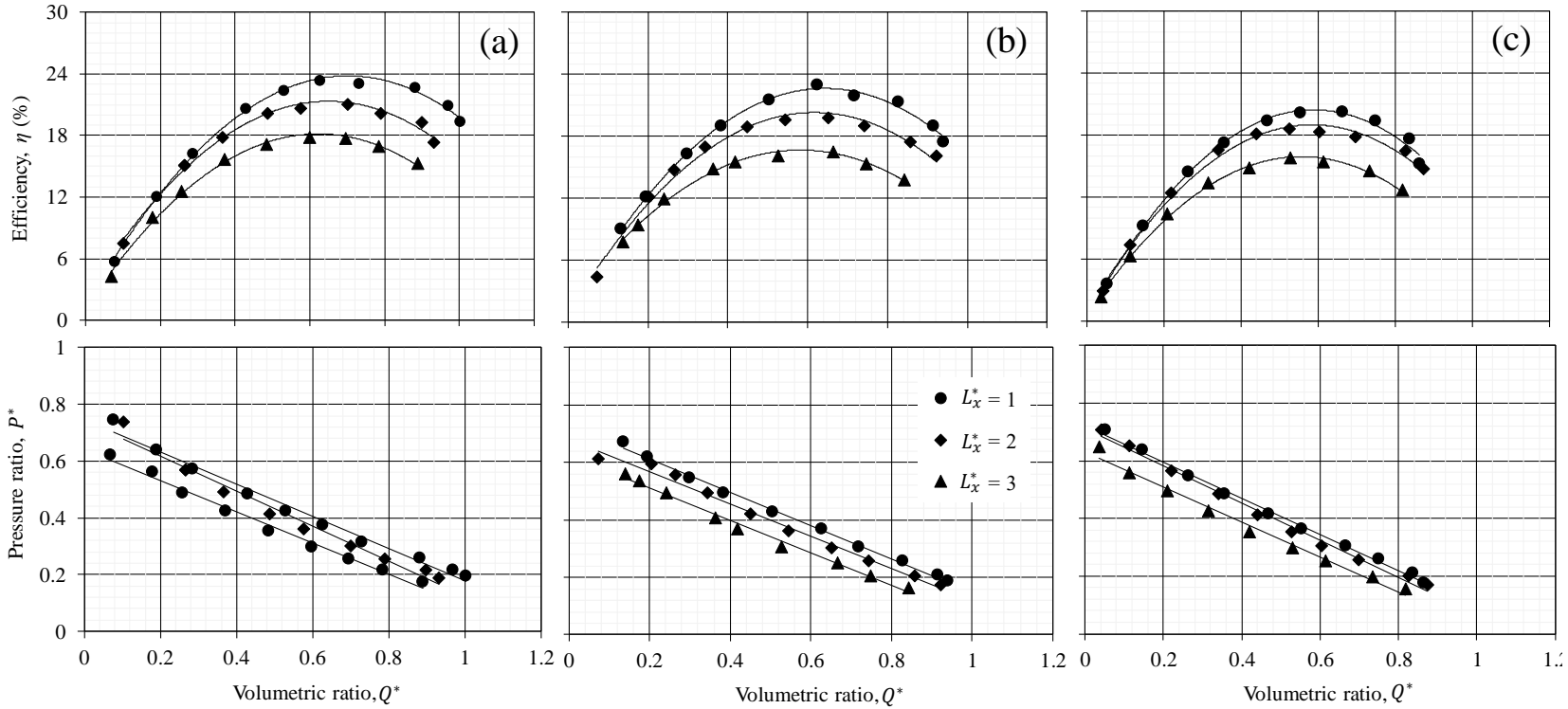

Figure 5. Performance and pressure ratio characteristic curves at constant throat-aspect ratio: (a) $\boldsymbol{L}_{t}^{*}=5$, (b) $\boldsymbol{L}_{t}^{*}=7$ and (c) $\boldsymbol{L}_{\boldsymbol{t}}^{*}=9$

Concerning to standard configuration of water jet pump design, which is represented by $L_{x}^{*}=1$ and $L_{t}^{*}=7$, as discussed in the previous section, Figure 5(b) depicts that the highest efficiency is about $22.91 \%$ standard design. It can be noticed that by reducing $L_{t}^{*}$ from 7 to 5 , the efficiency increases by about $0.6 \%$. However, it does not happen when increasing the projection ratio. Figure 5(c) illustrates the efficiency and pressure ratio curve of extending of $L_{t}^{*}$ to 9 . The $Q_{\max }^{*}$ decreases from 1.0 to 0.86 , while the optimum $P^{*}$ declines from 0.37 to 0.36 for each projection ratio. Varying $L_{x}^{*}$ from 1 to 3 times decrease efficiency by about $4.5 \%$ of $21.02 \%$. Also, extending the throat-aspect ratio of about $80 \%$ from 5 to 9 causes efficiency drops by about $3 \%$. Typically, a jet pump having a prolonged throat is penalised by friction losses in the throat. Also, the shorter throat resulted in the continuation of mixing into the diffuser with associated performance loss.

Regarding nine configurations of testing results, the best configuration was identified at $L_{x}^{*}=1$ and $L_{t}^{*}=5$. Even though the configuration offers the highest efficiency, it is restricted at constant driving pressure and outlet nozzle area ratio. Future study is required to investigate the limitation of efficiency by considering another parameter, i.e., working 
conditions and fluid density. Since the material of the jet pump in this study is not transparent material, the whole process in each test point cannot be observed directly. Nonetheless, the phenomena that occurred in the jet pump can be noticed by some indicators (pressure gauge and transparent tube) and signs, e.g. noise sound or vibration.

Figure 6 illustrates the characteristic curve and relation between $Q^{*}$ and $P^{*}$ at the best efficiency point at the normal operating condition. The analysing starts from the left area of the breakdown line may direct to the reversed flow. At this point, the jet and secondary flow are fallen to the suction pipe, which is known from intense noise and vibration assigns. There is no entrained flow on the flow meter indicator, and the vacuum pressure is not generated. It may be happened due to insufficient momentum transfer to handle high backpressure. Finally, the jet pump becomes malfunctions. As a result of recirculation, the efficiency declined rapidly due to the blocking of secondary flow. The visualisation of recirculation under varying back pressure can be seen in our previous work [9]. Increasing volumetric ratio from breakdown pressure line to a critical pressure line designated that there is unchoked secondary flow. The phenomena sign can be noticed from the pressure tube vibration. This condition emphasised that momentum transfer was dissipated earlier due to decreasing backpressure at the throat entry. As a consequence, the volumetric ratio increased, and the pressure ratio decreased. The critical pressure line specifies the equality value between jet dynamics pressure and backpressure. At this point, the jet pump reaches the limit of momentum transfer to the secondary flow. The declining backpressure at the end of the throat is spotted by pressure differential and pointed in a transparent tube. Later, the process is finalised by generating vacuum pressure in the chamber due to the momentum transfer; the secondary flow is entrained immediately, which is known as a choking phenomena. Increasing back pressure in the outlet caused decreasing $Q^{*}$ and increasing $P^{*}$ simultaneously.

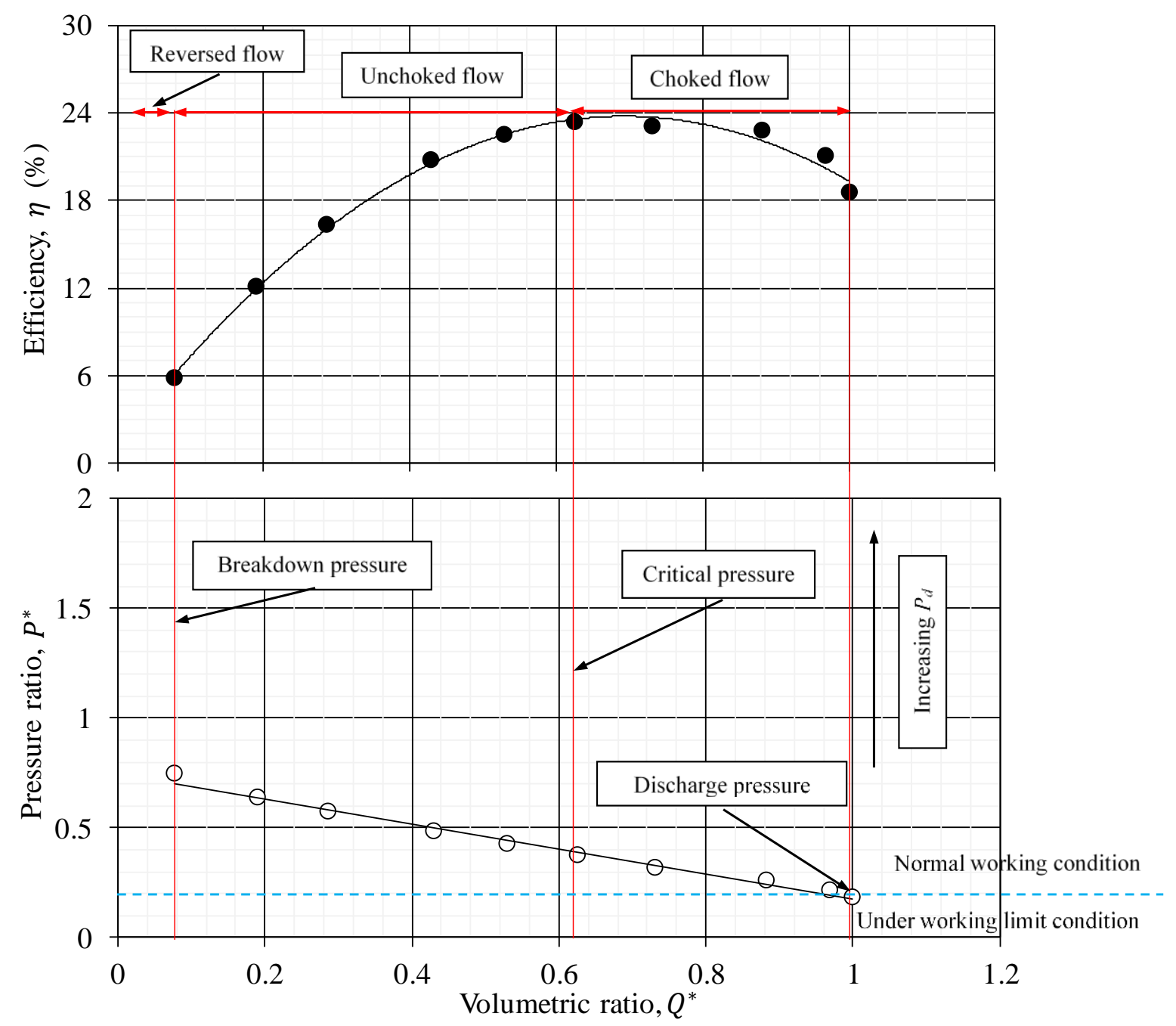

Figure 6. Efficiency and pressure ratio characteristic curves at the best configuration: at $\boldsymbol{L}_{\boldsymbol{x}}^{*}=1$ and $\boldsymbol{L}_{\boldsymbol{t}}^{*}=5$

\section{Loss Coefficient Evaluation}

The friction loss coefficient $(K)$ of throat and diffuser were required to be determined and evaluated. Figure 7 depicts the effect of both ratios, i.e. $L_{x}^{*}$ and $L_{t}^{*}$ on the friction loss coefficient of the throat and diffuser. It is useful to know the effect of improving jet pump efficiency. The dashed line represents the recommendation of the friction loss coefficient as low as 0.1 to achieve the highest performance [34]. Both loss coefficients tend to decrease with increasing $Q^{*}$. It emphasised that the loss coefficient is not constant under different operating conditions and geometry parameters. The 
loss coefficient of the diffuser $\left(K_{d}\right)$ is relatively higher than the throat section $\left(K_{t}\right)$. For instance, the throat loss coefficient at a low projection ratio $\left(L_{x}^{*}=1\right)$ and at a short throat-aspect ratio $\left(L_{t}^{*}=5\right)$ is higher than the other projection ratio. As a consequence, the diffuser loss coefficient becomes lower than its projection ratios as well.
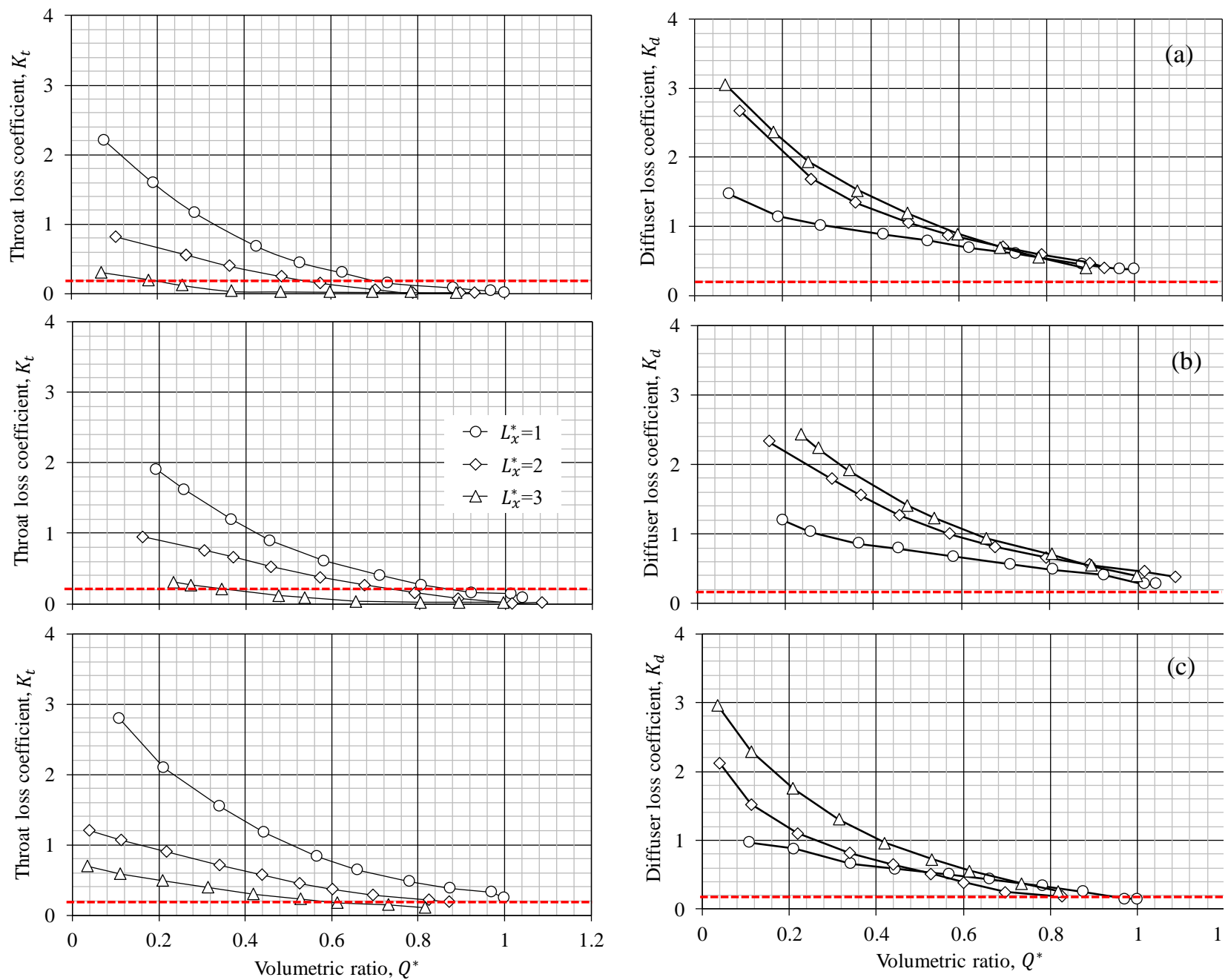

Figure 7. Friction loss coefficients $(\boldsymbol{K})$ in the throat and diffuser section: $\boldsymbol{L}_{t}^{*}=5$ (top), $\boldsymbol{L}_{t}^{*}=7$ (middle) and $\boldsymbol{L}_{t}^{*}=9$ (bottom)

However, an interesting point can be learned from the changes in the loss coefficient of throat and diffuser related to efficiency. Adjusting appropriate $L_{x}^{*}$ and $L_{t}^{*}$ is responsible for maintaining $K_{t}$ and $K_{d}$. In general, the lower value $K_{t}$ and $K_{d}$, the higher efficiency is obtained. Figure 8 illustrates the loss coefficient of different throat-aspect ratios at a constant projection ratio $\left(L_{x}^{*}=1\right)$. Extending the throat-aspect ratio effects the loss coefficient in the throat and diffuser section sequentially. For example, increasing $L_{t}^{*}$ leads increasing on $K_{t}$ and decreasing on $K_{d}$. Figure 8(a) shows that $K_{t}$ is lower than $K_{d}$ at $Q^{*}<0.35$ and it surpasses $K_{d}$ at $Q^{*}>0.35$. The surpassing $K_{t}$ indicates that the intense friction process may happen in the throat. Figure 8(b) depicts that the friction process initially starts in the throat and finally ends in the diffuser. At this condition, the friction location can be identified from $K_{t}$ and $K_{d}$ values. The higher value may indicate the dominant friction location. The effect can be seen in Figure 8(c), where extending $L_{t}^{*}$ from 5 to 9 leads the dominant friction process in the throat. 

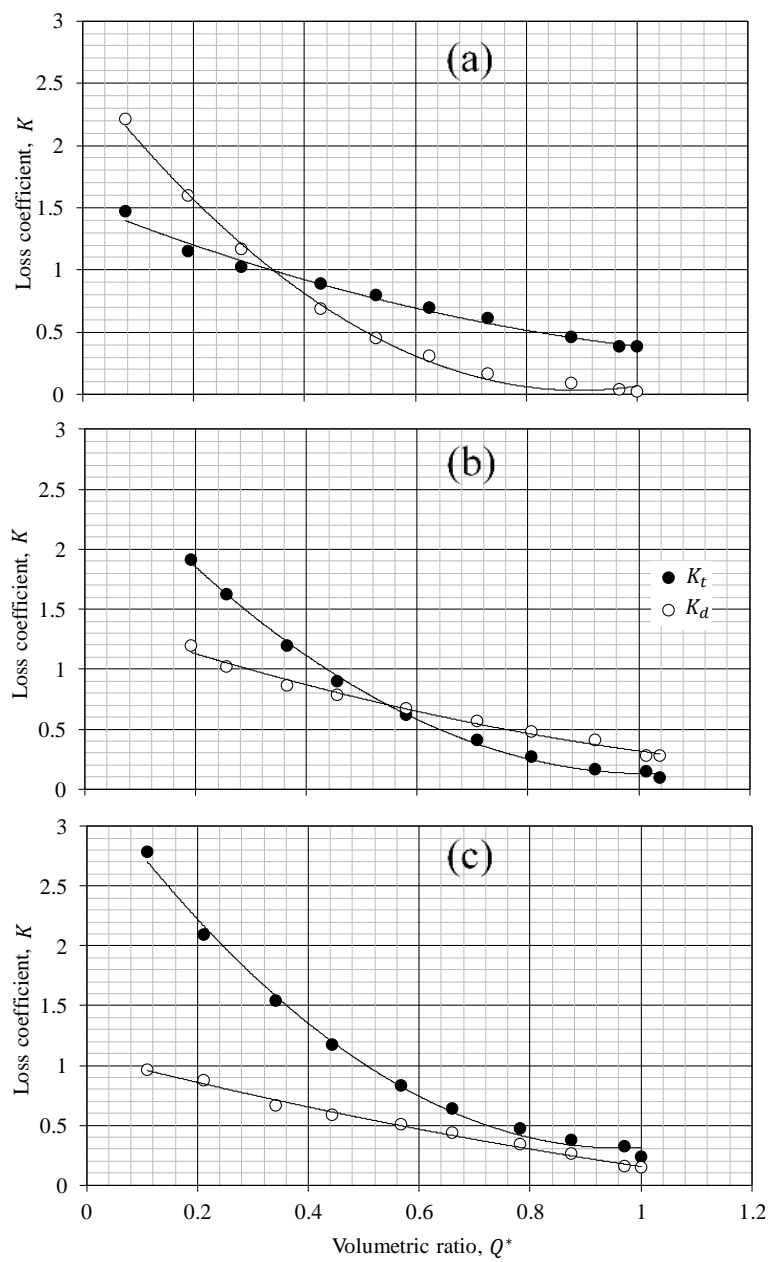

Figure 8. Friction loss coefficients $(\boldsymbol{K})$ in the throat and diffuser section $\left(\boldsymbol{L}_{\boldsymbol{x}}^{*}=1\right)$ at difference throat-aspect ratio: (a) $\boldsymbol{L}_{t}^{*}=5$, (b) $\boldsymbol{L}_{t}^{*}=7$ and (c) $\boldsymbol{L}_{t}^{*}=9$

\section{CONCLUSIONS}

This experiment aims to investigate the influence of projection and throat-aspect ratios on the efficiency and friction loss coefficient of the water jet pump with constant throat diameter. Three different values of both ratios are provided for experimental investigation. Constant driving pressure and varying back pressure are applied to achieve the efficiency curve. As results, the maximum and minimum efficiency of each configuration are noticed at $L_{x}^{*}=1$ and $L_{x}^{*}=3$ for each throat-aspect ratio $\left(L_{t}^{*}\right)$. Decreasing $L_{t}^{*}$ from 9 to 5 raises efficiency by about $3 \%$. Shorter of $L_{t}^{*}$ may cause loss of kinetic energy in the diffuser, while longer $L_{t}^{*}$ reduces momentum transfer on the secondary flow. Later, the friction loss coefficient can be noticed by increasing noise and vibration during increasing backpressure. Decreasing friction loss coefficient may indicate the disappearance of recirculation flow. It can be accounted for from the rising flow rate in the outlet and it is also associated with decreasing energy loss. Improper $L_{x}^{*}$ and $L_{t}^{*}$ the configuration may impact the degradation of efficiency gradually. In essence, the experiment denotes the best efficiency is about $23.37 \%$, which is identified at $L_{x}^{*}=1$ and $L_{t}^{*}=5$. The efficiency is acceptable, and the configuration is agreed well with the ESDU standard. In addition, the best efficiency of each configuration is recognised close to $2 / 3$ of the maximum volumetric ratio or maximum backpressure. Hence, the value of projection ratio and throat-aspect ratio plays a role where the kinetic energy loss occurs. However, another testing involving different parameters is required to enhance and to explore the information of jet pump behaviour. Further study is planned to focus on the sensitivity analysis for improving efficiency to the maximum via CFD simulation.

\section{ACKNOWLEDGEMENTS}

The authors would like to express their gratitude to the Faculty of Engineering, The Petchra Pra Jom Klao PhD scholarship, Grant No. 1/2559, the King Mongkut's University of Technology Thonburi and Center for Energy Technology and Environment (CEE), PERDO, Ministry of Higher Education, Science, Research and Innovation for the financial support provided to perform this study. 


\section{REFERENCES}

[1] I. E. L. Neto, 'Maximum suction lift of water jet pumps', J. Mech. Sci. Technol., vol. 25, no. 2, pp. 391-394, 2011, doi: 10.1007/s12206-010-1221-7.

[2] ESDU, ESDU 85032 Ejectors and jet pumps Design and performance for incompressible liquid flow. Engineering Science Data Unit, 2007.

[3] X. Long, H. Yao, and J. Zhao, 'Investigation on mechanism of critical cavitating flow in liquid jet pumps under operating limits', Int. J. Heat Mass Transf., vol. 52, no. 9, pp. 2415-2420, 2009, doi: https://doi.org/10.1016/j.ijheatmasstransfer.2008.11.018.

[4] L. Xiao and X. Long, 'Cavitating flow in annular jet pumps', Int. J. Multiph. Flow, vol. 71, pp. 116-132, 2015, doi: https://doi.org/10.1016/j.ijmultiphaseflow.2015.01.001.

[5] L. Z. Xiao, X. P. Long, Q. Lyu, Y. Hu, and Q. Q. Wang, 'Numerical investigation on the cavitating flow in annular jet pump under different flow rate ratio', IOP Conf. Ser. Earth Environ. Sci., vol. 22, no. 5, p. 52001, 2014, doi: 10.1088/1755$1315 / 22 / 5 / 052001$.

[6] X. Wang, Y. Chen, M. Li, Y. Xu, B. Wang, and X. Dang, 'Numerical investigation of the cavitation performance of annular jet pumps with different profiles of suction chamber and throat inlet', Eng. Appl. Comput. Fluid Mech., vol. 14, no. 1, pp. 1416-1428, Jan. 2020, doi: 10.1080/19942060.2020.1824875.

[7] L. Xiao, X. Long, X. Li, Q. Zeng, and X. Yang, 'Numerical investigation on the recirculation in annular jet pumps', J. Mech. Sci. Technol., vol. 27, no. 6, pp. 1603-1609, 2013, doi: 10.1007/s12206-013-0406-2.

[8] L. Xiao, X. Long, and J. Zhang, 'Shear cavitation in an annular jet pump under recirculation conditions', J. Fluids Eng., vol. 138, no. 6, Mar. 2016, doi: 10.1115/1.4032487.

[9] M. P. Helios and W. Asvapoositkul, 'Visualization of flow behavior and performance analysis of horizontal central-driven ejector system', in 15th Asian Symposium on Visualization, 2019, pp. 1-11.

[10] C. Prabkeao and K. Aoki, 'Study on the optimum mixing throat length for drive nozzle position of the central jet pump', $J$. Vis., vol. 8, no. 4, pp. 347-355, 2005, doi: 10.1007/BF03181554.

[11] K. Aldaş and R. Yapıc1, 'Investigation of effects of scale and surface roughness on efficiency of water jet pumps using CFD', Eng. Appl. Comput. Fluid Mech., vol. 8, no. 1, pp. 14-25, Jan. 2014, doi: 10.1080/19942060.2014.11015494.

[12] T. A. Meakhail and I. R. Teaima, 'Experimental and numerical studies of the effect of area ratio and driving pressure on the performance of water and slurry jet pumps', Proc. Inst. Mech. Eng. Part C J. Mech. Eng. Sci., vol. 226, no. 9, pp. 2250-2266, Nov. 2011, doi: 10.1177/0954406211430458.

[13] M. Nasr, M. A. Hosien, E. M. Wahba, and A. A. A. Sheha, 'Computational and experimental study on the water-jet pump performance under different geometrical and operational parameters', ERJ. Eng. Res. J., vol. 40, no. 2, pp. 107-117, 2017, doi: 10.21608/erjm.2017.66340.

[14] A. H. Hammoud, 'Effect of design and operational parameters on jet pump performance', in 4th WSEAS International Conference on Fluid Mechanics and Aerodynamics, 2006, pp. 245-252.

[15] A. A. Saker and H. Z. Hassan, 'Study of the different factors that influence jet pump performance', Open J. Fluid Dyn., vol. 3, no. 2, pp. 44-49, 2013, doi: 10.4236/ojfd.2013.32006.

[16] S. R. Pandhare and A. K. Pitale, 'Study the performance of water jet pump by changing the angle of mixing nozzle', Int. J. Sci. Res. Sci. Technol., vol. 3, no. 3, pp. 538-540, 2017, doi: 10.32628/IJSRST1733189.

[17] J. Toteff and M. Asuaje Tovar, 'Design and multiparameter optimization of jet-pumps in a pipeline loops using CFD tools', in 2nd Symposium on Development and Applications in Computational Fluid Dynamics, 2018, pp. 1-10, doi: 10.1115/FEDSM2018-83440.

[18] A. A. A. Sheha, M. Nasr, M. A. Hosien, and E. M. Wahba, 'Computational and experimental study on the water jet pump performance', J. Appl. Fluid Mech., vol. 11, no. 4, pp. 1013-1020, 2018, doi: 10.18869/acadpub.jafm.73.247.28407.

[19] J. Tang, Y. Zhou, J. Liu, J. Wang, and W. Zhu, 'Liquid metal actuated ejector vacuum system', Appl. Phys. Lett., vol. 106, no. 3, p. 031901, Jan. 2015, doi: 10.1063/1.4906098.

[20] Y. I. Kryzhanivskyi and D. O. Panevnyk, 'The study on the flows kinematics in the jet pump's mixing chamber', Geotech. Min. Mech. Eng. Mach. Build., vol. 1, pp. 62-68, 2019, doi: 10.29202/nvngu/2019-1/7.

[21] J. Tang, Z. Zhang, L. Li, J. Wang, J. Liu, and Y. Zhou, 'Influence of driving fluid properties on the performance of liquiddriving ejector', Int. J. Heat Mass Transf., vol. 101, pp. 20-26, 2016, doi: https://doi.org/10.1016/j.ijheatmasstransfer.2016.04.028.

[22] S. A. Gaade, M. M. Awad, A. R. Dohina, and W. M. El-Awady, 'The performance of hybrid centrifugal-jet pump', Int. J. Eng. Sci. Res. Technol., vol. 5, no. 11, pp. 484-490, 2016, doi: 10.5281/zenodo.168433.

[23] M. Suzuki, K. Tanaka, and S. Sakuragi, 'The operating characteristic of an underwater jet pump', in 3rd IPEJ Conference on Research Achievements, 2016, pp. 1-4.

[24] S. Zhao and S. Sakuragi, 'Performance improvement of underwater jet pump by optimal arrangement of primary jet stream', J. Fluid Sci. Technol., vol. 13, no. 1, pp. 1-11, 2018, doi: 10.1299/jfst.2018jfst0004.

[25] S. Sakuragi and S. Zhao, 'Operating characteristics of multi-injection type underwater jet pump', Am. J. Mech. Appl., vol. 6, no. 3, pp. 58-67, 2018, doi: 10.11648/j.ajma.20180603.11. 
[26] R. G. Cunningham, 'Liquid jet pumps for two-phase flows', J. Fluids Eng., vol. 117, no. 2, pp. 309-316, Jun. 1995, doi: 10.1115/1.2817147.

[27] N. L. Sanger, 'An experimental investigation of several low-area-ratio water jet pumps', J. Basic Eng., vol. 92, no. 1, pp. 1119, Mar. 1970, doi: 10.1115/1.3424917.

[28] A. E. Kroll, 'The design of jet pumps', Chem. Eng. Prog., vol. 1, no. 2, pp. 21-24, 1947.

[29] J. M. A. Dandachi, 'Steam air ejector performance and its dimensional parameters', Ph.D. dissertation, Dept. Chem. Eng., Loughborough Univ., Loughborough, UK, 1990.

[30] R. G. Cunningham, 'Gas compression with the liquid jet pump', J. Fluids Eng., vol. 96, no. 3, pp. 203-215, 1974, doi: 10.1115/1.3447143.

[31] S. P. Mehta, 'A study of water jet pumps', M. S. Thesis, Dept. Mech. Eng., Kansas State Univ., Manhattan, USA, 1968.

[32] A. H. Hammoud and A. A. Naby, 'Slurry jet pump performance: under different Ddesign and operational parameters', in 4th WSEAS International Conference on Fluid Mechanics and Aerodynamics, 2006, pp. 237-244.

[33] I. A. El-Sawaf, M. A. Halawa, M. A. Younes, and I. R. Teaima, 'Study of the different parameters that influence on the performance of water jet pump', in 15th International Water Technology Conference, 2011, pp. 1-17.

[34] T. A. Meakhail and I. R. Teaima, 'A study of the effect of nozzle spacing and driving pressure on the water jet pump performance', Int. J. Eng. Sci. Innov. Technol., vol. 2, no. 5, pp. 373-382, 2013.

[35] H. Herwig and B. Schmandt, 'Drag with external and pressure drop with internal flows: A new and unifying look at losses in the flow field based on the second law of thermodynamics', Fluid Dyn. Res., vol. 45, no. 5, p. 55507, 2013, doi: 10.1088/01695983/45/5/055507.

[36] B. R. Munson 1940-, Fundamentals of fluid mechanics. Seventh edition. Hoboken, NJ : John Wiley \&amp; Sons, Inc., [2013].

[37] H. Herwig and B. Schmandt, 'How to determine losses in a flow field: a paradigm shift towards the second law analysis', Entropy, vol. 16, no. 6, 2014, doi: 10.3390/e16062959.

[38] ESDU, ESDU 93022 Ejector and jet pump: computer program for design and performance for liquid Flow. Engineering Science Data Unit, 2011.

[39] Test uncertainty PTC 19.1 - 2005. ASME, 2007.

[40] S. Kline, 'Describing uncertainties in single-sample experiments', Mech. Eng., vol. 75, pp. 3-8, 1953. 